Plant Molecular Biology 18: 179-180, 1992.

(C) 1992 Kluwer Academic Publishers. Printed in Belgium.

Erratum

\title{
Transgene expression variability (position effect) of CAT and GUS reporter genes driven by linked divergent T-DNA promoters
}

Cindy Peach ${ }^{1,3}$ and Jeff Velten ${ }^{1,2,3, *}$

${ }^{1}$ Graduate Program in Molecular Biology (" author for correspondence); ${ }^{2}$ Plant Genetic Engineering Laboratory, and ${ }^{3}$ Chemistry Department, New Mexico State University, Las Cruces, NM 88003-0001, $U S A$

Plant Molecular Biology 17: 49-60, 1991.

In Table 1 on p. 53 of the above article, the CAT activity data is misplaced by a single line. We now present the corrected table in full overleaf. 
Table 1. Pmas1' $\rightarrow$ CAT and Pmas2' $\rightarrow$ GUS activities within clonal transgenic tobacco callus lines.

\begin{tabular}{|c|c|c|c|}
\hline Callus line identifier & $\begin{array}{l}\text { CAT activity }{ }^{1,2} \\
(\mathrm{nmol} / \mathrm{min} / \mathrm{mg})\end{array}$ & $\begin{array}{l}\text { GUS activity } 1,2 \\
(\mathrm{nmol} / \mathrm{min} / \mathrm{mg})\end{array}$ & $\begin{array}{l}\text { Ratio of activities }{ }^{2,3} \\
\text { GUS/CAT }\end{array}$ \\
\hline GC4-NP & 0 & 0 & $\mathrm{NC}$ \\
\hline GC4-00.1 & 78.99 & 15 & 0.19 \\
\hline GC4-00.2 & 29.52 & 285 & 9.65 \\
\hline GC4-00.3 & 41.80 & 1,434 & 34.30 \\
\hline GC4-00.4 & 34.86 & 980 & 28.11 \\
\hline GC4-00.5 & 25.84 & 609 & 23.55 \\
\hline GC4-00.6 & 2.43 & 16 & 6.53 \\
\hline GC4-00.7 & 60.13 & 1,298 & 21.58 \\
\hline GC4-00.8 & 1.86 & 15 & 8.02 \\
\hline GC4-00.9 & 71.51 & 272 & 3.81 \\
\hline GC4-00.10 & 98.59 & 485 & 4.92 \\
\hline GC4-00.11 & 0 & 0 & $\mathrm{NC}$ \\
\hline GC4-00.12 & 40.91 & 1,109 & 27.11 \\
\hline GC4-00.13 & 56.94 & 597 & 10.49 \\
\hline GC4-00.14 & 60.87 & 192 & 3.16 \\
\hline GC4-00.15 & 53.40 & 18 & 0.34 \\
\hline GC4-00.16 & 22.30 & 0 & $\mathrm{NC}$ \\
\hline GC4-00.17 & 14.45 & 419 & 29.03 \\
\hline GC4-00.18 & 0 & 0 & $\mathrm{NC}$ \\
\hline GC4-00.19 & 73.29 & 578 & 7.88 \\
\hline GC4-00.20 & 30.89 & 1,513 & 48.99 \\
\hline GC4-00.21 & 247.39 & 14 & 0.06 \\
\hline GC4-00.22 & 97.60 & 625 & 6.40 \\
\hline GC4-00.23 & 0 & 0 & $\mathrm{NC}$ \\
\hline GC4-00.24 & 33.89 & 731 & 21.58 \\
\hline GC4-00.25 & 65.39 & 631 & 9.65 \\
\hline GC4-00.26 & 0 & 0 & $\mathrm{NC}$ \\
\hline GC4-00.27 & 23.00 & 471 & 20.49 \\
\hline GC4-00.28 & 26.55 & 328 & 12.36 \\
\hline GC4-00.29 & 62.29 & 1,337 & 21.46 \\
\hline GC4-00.30 & 56.13 & 1,423 & 25.35 \\
\hline GC4-00.31 & 38.16 & 1,214 & 31.80 \\
\hline GC4-00.32 & 3.49 & 0 & $\mathrm{NC}$ \\
\hline GC4-00.33 & 135.11 & 33 & 0.25 \\
\hline GC4-00.34 & 67.39 & 805 & 11.95 \\
\hline GC4-00.35 & 36.21 & 1,290 & 35.63 \\
\hline GC4-00.36 & 49.48 & 849 & 17.16 \\
\hline GC4-00.37 & 43.26 & 847 & 19.58 \\
\hline GC4-00.38 & 54.48 & 2,447 & 44.92 \\
\hline GC4-00.39 & 253.33 & 14 & 0.05 \\
\hline GC4-00.40 & 62.16 & 1,492 & 24.01 \\
\hline GC4-00.41 & 0 & 0 & $\mathrm{NC}$ \\
\hline GC4-00.42 & 4.67 & 0 & $\mathrm{NC}$ \\
\hline GC4-00.43 & 17.36 & 810 & 46.66 \\
\hline GC4-00.44 & 36.18 & 881 & 24.34 \\
\hline GC4-00.45 & 57.80 & 0 & $\mathrm{NC}$ \\
\hline
\end{tabular}

${ }^{1}$ Values indicated by ' 0 ' were less then two times the background values for the no promoter (GC4-NP) callus (CAT $<0.12 \mathrm{nmol} /$ $\mathrm{min} / \mathrm{mg}$ and GUS $<4.5 \mathrm{nmol} / \mathrm{min} / \mathrm{mg}$ ).

2 Values in bold are the maximum and minimum values for that column.

${ }^{3}$ GUS/CAT ratios were not calculated (NC) when one or both activities were zero. 